\title{
A CONTRIBUIÇÃO DA PSICANÁLISE PARA O TRATAMENTO DE PSICÓTICOS NA REDE DE ATENÇÃO PSICOSSOCIAL (RAPS): REVISÃO BIBLIOGRÁFICA
}

\section{ARTIGO ORIGINAL}

COSTA, Alex Junio Duarte ${ }^{1}$

COSTA, Alex Junio Duarte. A contribuição da psicanálise para o tratamento de psicóticos na Rede de Atenção Psicossocial (RAPS): Revisão bibliográfica. Revista Científica Multidisciplinar Núcleo do Conhecimento. Ano 05, Ed. 12, Vol. 14, pp. 171-187. Dezembro de 2020. ISSN: 2448-0959, Link de acesso: https://www.nucleodoconhecimento.com.br/psicologia/tratamento-depsicoticos

\section{RESUMO}

As famigeradas instituições de saúde mental têm importante papel no acompanhamento de indivíduos que são portadores de sofrimento ou transtorno psíquico. Frente aos avanços das legislações que versam sobre o tema. Cada vez mais estas instituições necessitam de mão de obra especializada e vislumbram o respeito aos direitos humanos e tratamento conforme a demanda dos seus pacientes no intuito de personalizar e otimizar os resultados. A Psicanálise como disciplina autônoma, com meios técnicos e ferramentas próprias que buscam estar centradas no indivíduo e suas particularidades possui valores que vão ao encontro aos que essas instituições almejam. Assim, a presente pesquisa se propôs a verificar como a Psicanálise poderá contribuir para o melhor engajamento dos pacientes psicóticos, familiares e das equipes multiprofissionais nas instituições de saúde mental, buscando acolher as demandas inerentes a própria disciplina psicanalítica que apareçam nessa tríade e também fazer um trabalho multidisciplinar e transdisciplinar. Foram verificados

\footnotetext{
${ }^{1}$ Psicólogo, Especialista em Saúde Mental e Atenção Psicossocial e Especialista em Política e Sociedade.
} 
diversos materiais bibliográficos entre livros, artigos, portarias, resoluções e leis, sendo retirados de diversas bases de dados como LILACS, SciELO, dentre outros. A abordagem selecionada foi a qualitativa e o recorte temporal feito para seleção dos trabalhos foi dos anos 1999 a 2020, dando preferência para os mais recentes. Concluise que a Psicanálise poderá contribuir de forma inigualável para as Redes de Atenção Psicossocial tendo em vista as atuais políticas e concepções que devem ser adotados por elas. Sugere-se estudos que englobe o advento da Psicanálise nos hospitais psiquiátricos e outros que abarquem a disciplina em oficinas de artes e musicoterapia.

Palavras-chave: Psicanálise, Saúde Mental, Atenção Psicossocial, Psicose.

\section{INTRODUÇÃO}

A Rede de Atenção Psicossocial (RAPS) propõe um trabalho em conjunto das instituições que oferecem acompanhamento em saúde mental com intuito de garantir o acesso e promoção do direito das pessoas, estimulando e fundamentando o acompanhamento a partir da convivência em sociedade (BRASIL, 2011/2013; NOBREGA; MANTOVANI; DOMINGOS, 2020).

Tendo em vista as diretrizes da RAPS que visam antes de tudo o respeito aos direitos humanos e a garantia da autonomia e liberdade das pessoas, o método de acompanhamento de um paciente portador de sofrimento psíquico e/ou transtorno mental deve ter uma equipe altamente especializada e que enxerguem frente a eles um indivíduo que, mesmo com as limitações aparentes, deve ter sua autonomia e valores preservados e respeitados (BRASIL, 2011/2013).

A Psicanálise por sua vez, é uma disciplina autônoma que dispõe de teorias e técnicas qualitativas para se a ver com o sofrimento psíquico do sujeito, podendo contribuir de forma ímpar no acompanhamento de pacientes psicóticos nas instituições integrantes da RAPS (ALBERTI, 2008; ALBERTI; FULCO, 2005; COPPUS; NETTO, 2016; SANTOS; OLIVEIRA, 2012). Frente a isto, o presente trabalho buscou verificar qual a aplicabilidade da Psicanálise e suas teorias no contexto institucional das organizações articuladoras da Rede de Atenção Psicossocial (RAPS). 
Pela forma singular de proposta de acompanhamento ao paciente feita pela Psicanálise que vão ao encontro ao método proposto pelas novas organizações e estratégias de tratamento em saúde mental, a disciplina psicanalítica poderá se tornar uma ferramenta contributiva para um tratamento mais humanizado e individualizado, com respeito ao indivíduo, seu saber singular sobre si e sua experiência psíquica, corporal e social. Além disto, o psicanalista será capaz de auxiliar na ampliação dos olhares da equipe multidisciplinar podendo ainda, ajudar na resolução de questões internas e pessoais desta, evitando assim, que isto prejudique o tratamento (ALBERTI, 2008; COPPUS; NETTO, 2016; MONTEIRO; QUEIROZ, 2006; NEVES; OMENA, 2016)

Quanto à relevância da pesquisa acerca dessa temática, é percebido que ela assimila a possibilidade de contribuição social no que tange a pertinência em se ter um psicanalista na equipe multiprofissional das instituições de saúde mental e, a partir disso, como ele poderá contribuir para a evolução da compreensão do indivíduo psicótico e desenvolvimento de seu tratamento. Ademais, a pesquisa se torna pertinente à medida que poderá contribuir para a evolução dos conhecimentos referentes ao acompanhamento do paciente que tem sofrimento ou transtorno mental dentro das instituições e a partir da ótica psicanalítica.

Nesta lógica, o presente estudo teve como objetivo geral: verificar como se dá a contribuição da Psicanálise no tratamento de pacientes psicóticos dentro das instituições da Rede de Atenção Psicossocial. E como objetivos específicos este trabalho se dispõe a: 1) investigar como é visto o indivíduo psicótico e as formas tratamento possíveis dentro das instituições a partir da ótica psicanalítica; 2) entender como o a Psicanálise adentra nas instituições sem se perder ou desviar de sua ética, 3) verificar a possibilidade de interação da psicanálise com outras disciplinas, contribuindo para a evolução da equipe multidisciplinar.

O tipo de trabalho realizado foi a revisão bibliográfica, onde foram investigados livros, artigos, leis, resoluções e portarias que pudessem contribuir para a compreensão do funcionamento das RAPS e da efetividade da Psicanálise dentro das instituições de saúde mental e como estas são organizadas. Frente a isto, foram analisados diversos 
materiais bibliográficos e foi possível constatar que instituições que têm um psicanalista dentro da equipe multiprofissional conseguem the dar melhor com os pacientes psicóticos e suas respectivas famílias, dando um tratamento isonômico e também respeitando as diferenças de cada indivíduo e seus saberes singulares sobre seu problema.

Além disto, instituições que têm um psicanalista, podem ter um intermediador de conflitos internos, facilitando as resoluções destes e reduzindo os riscos de impacto no desenrolar dos tratamentos. Similarmente, existe a possibilidade de o psicanalista intervir para auxiliar membros da equipe multiprofissional em problemas externos ao serviço que afetam o colaborador e sua respectiva função dentro da organização.

\section{REFERENCIAL TEÓRICO}

\subsection{A REDE DE ATENÇÃO PSICOSSOCIAL, O PSICANALISTA E A EQUIPE MULTIPROFISSIONAL}

A clínica particular psicanalítica é considerada uma clínica feita para neuróticos, onde estes, junto com seus analistas, irão trabalhar a falta e o sofrimento psíquico que são advindos do seu tipo de neurose, podendo ser histérica ou obsessiva (ALMEIDA, 2017; COPPUS; NETTO, 2016; MONTEIRO; QUEIROZ, 2006; SANTOS; OLIVEIRA, 2012). Ante o avanço das teorias e pesquisas em Psicanálise, principalmente após o advento das teorias lacanianas, é possível conceber as técnicas desta disciplina para atendimentos que extrapolam a clínica tradicional e valer-se de suas ferramentas e concepções que se pautam a partir da visão do indivíduo, de suas realidades e singularidades para elaborar o projeto terapêutico que amplia os olhares $e$ possibilidades de atendimento para psicóticos na Rede de Atenção Psicossocial RAPS (ALMEIDA, 2017; COPPUS; NETTO, 2016).

A concepção arcaica de que os tratamentos oriundos da rede de saúde mental buscavam, da mesma forma que as intervenções nas enfermidades advindas do corpo, a erradicação total dos sintomas, deixou de ser pensada a partir da Reforma Psiquiátrica Brasileira da década de 1990, desde então uma série de legislações 
foram criadas para fortalecer as políticas públicas que visam garantir antes de tudo o bem estar e autonomia do paciente, de sua família e também dos funcionários responsáveis por receber e acompanhar esse tipo de público (BRASIL, 2011/2013; COPPUS; NETTO, 2016; MARANHÃO; VIEIRA, 2019; MONTEIRO; QUEIROZ, 2006).

Destarte, em 2011 esse movimento de busca de direitos para os que têm sofrimento psíquico e/ou é portador de transtorno mental ganhou ainda mais força com a instauração das redes de atenção em saúde mental, onde o acompanhamento se dá através de uma rede articulada com diferentes níveis de complexidade e equipes altamente especializadas na área as quais tornarão possível que os planos terapêuticos dos pacientes considerem as especificidades de cada um e seus possíveis prognósticos, passando a considerar as possibilidades e potencialidades de cada indivíduo (BRASIL, 2011/2013).

As famigeradas instituições de Saúde Mental que articuladas são chamadas de Rede de Atenção Psicossocial (RAPS) são as entidades responsáveis por atender pessoas que têm sofrimento ou transtorno mental e dispõe como parte das suas diretrizes o respeito aos direitos humanos, pela singularidade e autonomia do indivíduo (BRASIL, 2011/2013; NOBREGA; MANTOVANI; DOMINGOS, 2020). Tais instituições possuem uma equipe multiprofissional com grande capacitação na área que abrem um leque de possibilidades de assistências que abarcam algumas das necessidades comuns desse público, trazendo um tratamento que visam, dentre outras coisas, o cuidado integral, a redução de danos, a autonomia e liberdade das pessoas, bem como a participação dos familiares em todo o processo de trabalho (BRASIL, 2011/2013).

Isto posto, a práxis psicanalítica que tem por característica a individualização do acompanhamento e da escuta, parte do contexto geral da teoria para a singularização da escuta através das invenções, manejos clínicos, do caso a caso e em um ambiente propício, como na saúde mental, tende a adentrar de forma a contribuir para a otimização da individualização do tratamento e também para abarcar conteúdos advindos do paciente e suas particularidades que seriam deixadas de lado por outras disciplinas (COPPUS; NETTO, 2016; FIGUEIREDO, 2004; MARANHÃO; VIEIRA, 2019; NOBREGA; MANTOVANI; DOMINGOS, 2020). 
A Psicanálise adentra então, como uma forma de considerar o indivíduo, sua subjetividade e representações, o contexto no qual está inserido e os laços construídos por ele, permitindo um conhecimento único sobre o indivíduo e seu estágio de desenvolvimento diante das suas particularidades e sua relação com o corpo, criando soluções e possibilidades que podem passar despercebidas pela equipe multiprofissional (COPPUS; NETTO, 2016; FIGUEIREDO, 2004).

O psicanalista surge nessas instituições de saúde mental para auxiliar na singularização do acompanhamento criando uma "clínica do sujeito", buscando contribuir na introdução do psicótico como um sujeito que se constitui a partir da linguagem, seja qual for ela, podendo ser, por exemplo, um delírio onde haverá uma metáfora delirante e, por consequência, a estabilização do paciente (COPPUS; NETTO, 2016; MARANHÃO; VIEIRA, 2019; MONTEIRO; QUEIROZ, 2006).

Finalmente, o psicanalista terá a possibilidade de atuar como um profissional de escuta também da equipe multiprofissional e da família ajudando-os, na medida de suas necessidades, a simbolizarem e significarem aquilo que Ihes aparecem em seus respectivos contextos, onde os profissionais poderão encontrar, a título de exemplo, casos clínicos que podem remeter a algo da singularidade social de seus membros, podendo provocar interferências e prejuízos no andamento do acompanhamento (ALBERTI; FULCO, 2005; ALBERTI, 2008; COPPUS; NETTO, 2016; MARANHÃO; VIEIRA, 2019). A família, por sua vez, trará com o paciente a história dela, tendo seus vínculos e conflitos ressaltados ante o acompanhamento de um ente na rede de saúde mental, sendo estes dois tipos escuta supracitados, necessários para que o novo modelo de atenção psicossocial se constitua (MONTEIRO; QUEIROZ, 2006; NEVES; OMENA, 2016).

\subsection{A PSICANÁLISE INSTITUCIONAL NÃO-INSTITUCIONALIZADA}

Toda instituição possui uma forma de se organizar e distribuir tarefas, além disso, àquelas que trabalham com um público, em especial com o enfoque na dissolução e redução de problemas relacionados com saúde em geral, tendem a se organizar de forma singular para atender, padronizando os trabalhos naquele ambiente (ALBERTI, 
2008; ALBERTI; FULCO, 2005; COPPUS; NETTO, 2016; NOBREGA; MONTOVANI; DOMINGOS, 2020).

Diante disso, as equipes multidisciplinares, mesmo diante de suas singularidades acadêmicas e formas de conceber o tratamento, tende a compartilhar uma forma contextualizada e padronizada de enxergar a pessoa e suas enfermidades partindo do singular do primeiro caso que eles atendem, chegando à generalização ante a rotina, do olhar para pacientes com problemas semelhantes (ALBERTI, 2008; ALBERTI; FULCO, 2005; COPPUS; NETTO, 2016; NOBREGA; MONTOVANI; DOMINGOS, 2020).

O profissional psicanalista não estará isento de compartilhar essa visão generalista dos pacientes, contudo, a saber disso, ele deve ficar atento para que tais concepções não interfiram na clínica o levando a desconsiderar ou desvalorizar o indivíduo, sua subjetividade e o que conhece e fala de si mesmo, tendendo o tão perigoso método de saber centrado no especialista (COPPUS; NETTO, 2016; MONTEIRO; QUEIROZ, 2006; PORGE et al., 2015; SANTOS; OLIVEIRA, 2012).

Assim como a Psicanálise deve temer a padronização oriunda do poder público e das próprias concepções institucionais, que acabam forjando o enrijecimento de suas técnicas e metodologias de escuta, o analista pautado na ética da Psicanálise deverá abster-se de visões generalistas e centra-se em constituir um ambiente de escuta propício para que o paciente seja ouvido como o único que consegue falar de si mesmo, mesmo que este esteja em crise psicótica, pois será o delírio e suas representações que abrirá as portas para o analista começar a entender como se dá o modus operandi daquele paciente (COPPUS; NETTO, 2016; PORGE et al., 2015).

Sobre isto Coppus e Netto (2016) fazem uma importante consideração:

Assim, o psicólogo/psicanalista que atua na cena hospitalar não deve tentar se adequar ao modelo médico para poder "trabalhar em equipe" e atingir a meta de um discurso diferente do seu. Caso o faça, sua práxis se desviará radicalmente daquilo que constituiu a originalidade e a especificidade da clínica psicanalítica. Vale ressaltar que o trabalho do psicanalista no hospital, caso efetivamente consiga sua inserção, 
permite tratar um sujeito que há muito não pode ficar restrito à divisão cartesiana entre mente e corpo. O inconsciente demonstra que o corpo não é apenas orgânico e sim que ele é afetado pelo que se diz dele, pela maneira com que é representado, pelos afetos do homem (MILLER, 2014). É com esse corpo que ele adoece e é desse corpo, que muitas vezes, ele padece.

Esta consideração traga por Coppus e Netto (2016) não se limita apenas no contexto hospitalar, visto que a ética psicanalítica deve estar presente em todos os locais em que a própria análise oriunda desta vertente esteja e, como tal, se centra na escuta do indivíduo, pautando de mecanismo técnicos eficazes, mas sempre constituindo o ambiente terapêutico a partir do indivíduo, sendo que esta práxis ética é peça primordial no ato de fazer a clínica psicanalítica (ALBERTI; FULCO, 2005; COPPUS; NETTO, 2016; FIGUEIREDO, 2004).

Para psicanalista, além de um bom conhecimento de sua linha de trabalho e uma ética profissional, é necessário um feeling, se assim a doutrina permitir expor, onde devido a individualização e, por consequência, imprevisibilidade da clínica ele terá que saber exatamente o ponto em que poderá e terá que intervir, tendo cautela devido a fragilidade das organizações subjetivas do paciente psicótico. Por fim, este mesmo feeling é convocado novamente para que ele saiba o que é de interesse em ser repassado para a equipe multidisciplinar e o que ficará retido como informação sigilosa que será utilizada apenas no set clínico.

\subsection{A PSICOSE PARA A PSICANÁLISE}

Este artigo não pretende contemplar e nem esgotar toda a teoria psicanalítica que envolve o surgimento da estrutura clínica psicótica, apenas demostrar de forma sucinta um esboço de como ela surge e poderá ser trabalhada, na perspectiva psicanalítica.

À vista disso, para uma melhor compreensão do surgimento da estrutura psicótica para a Psicanálise é necessário um aprofundamento teórico, o qual não é objetivo deste artigo, então recomenda-se a leitura das obras que são consideradas marco teóricos sobre o tema para entender os processos psíquicos envolvidos, tais como: os 
três registros psíquicos, as três estruturas clínicas, o complexo de Édipo, Estádio do Espelho, lógica fálica, recalcamento, forclusão, denegação, castração e nome-do-pai, dentre outros (ARAGÃO E RAMIREZ, 2004; SANTOS; OLIVEIRA, 2012). Além disto, é amplamente recomendável a leitura do texto "Sobre a metáfora paterna e a foraclusão do nome-do-pai: uma introdução"[2] de Aragão e Ramirez (2004) para a melhor compreensão do restante do presente artigo.

\subsubsection{O MECANISMO DE DEFESA DA PSICOSE}

A psicose é uma das três estruturas clínicas dentro da Psicanálise tendo importante papel na subjetivação do indivíduo e no seu modus operandi (ARAGÃO E RAMIREZ, 2004). Logo, ela não é desencadeada apenas na crise como muitos leigos vêm a pensar, pois o indivíduo desenvolve esta estrutura bem antes da primeira crise, ainda no processo de desenvolvimento psicossexual ocorrido na primeira infância (ALMEIDA, 2017; ARAGÃO E RAMIREZ, 2004; SANTOS; OLIVEIRA, 2012).

O desenvolvimento das estruturas psíquicas no indivíduo na Psicanálise ocorre, conforme os trabalhos elaborados por Lacan (1955-1956/2008 apud SANTOS; OLIVEIRA, 2012), durante o processo da subjetivação da metáfora nome-do-pai[3] a qual é responsável por estabelecer no infante a castração simbólica marcando a inserção do indivíduo nos limites socioculturais e o consequente recalcamento de seus desejos ambivalentes que não poderão serem satisfeitos frente a esta limitação. Diante da impossibilidade de realização dos desejos do indivíduo devido a esta ambiguidade que Ihe é apresentada irá ocorrer a inauguração da lei, do limite e o surgimento do indivíduo neurótico como sujeito desejante e faltante (ARAGÃO E RAMIREZ, 2004; SANTOS; OLIVEIRA, 2012).

No psicótico, no entanto, o nome-do-pai não é instaurado, há uma falha metafórica onde o indivíduo terá a metáfora paterna posta para fora do simbólico, vindo a estar no real[4], ou seja, para aquilo que não é passivo de simbolizar na linguagem e por consequência, não haverá representação das leis no psicótico estando a metáfora paterna forclusa devido a este processo denominado de forclusão ou foraclusão (ARAGÃO E RAMIRES, 2004; SANTOS; OLIVEIRA, 2012). 
O termo forclusão é oriundo da tradução da palavra forclusion (que também é uma tradução feita por Lacan da palavra alemã Verwerfung) que é um vocábulo jurídico e equivale a dizer que o processo foi prescrito sem ter sido julgado em prazo hábil (ARAGÃO E RAMIRES, 2004; SANTOS; OLIVEIRA, 2012). Logo, a metáfora paterna perde seu lugar no simbólico e também a sua possibilidade de recurso, podendo dizer que a possibilidade de simbolização da castração e dos limites impostos pela inauguração da lei no infante expirou (ARAGÃO E RAMIRES, 2004; SANTOS; OLIVEIRA, 2012).

Então, acerca do conceito de foraclusão, Solal Rabinovich (2001 apud ARAGÃO E RAMIRES, 2004, p. 12) traz a pertinente concepção:

Assim, foracluir consiste em expulsar alguém ou alguma coisa para fora dos limites de um reino, de um indivíduo, ou de um princípio abstrato tal como a vida ou a liberdade; foracluir implica também o lugar, qualquer que ele seja, do qual se é expulso, seja fechado para todo o sempre... Foracluir consiste pois, afinal, em expulsar alguém para fora das leis da linguagem.

O sujeito psicótico é este que tem a metáfora paterna foraclusa que não possui representações psíquicas para ela e a coloca no campo do Real. É importante salientar que este mecanismo de defesa nomeado de forclusão tem enorme importância para a condução do caso clínico pois interfere na constituição primitiva do sujeito, alterando o seu saber inconsciente (ARAGÃO E RAMIRES, 2004; SANTOS; OLIVEIRA, 2012).

Em face disso, Aragão e Ramires (2004, p. 13) faz uma breve explicação dos mecanismos de defesa de cada estrutura psíquica:

Tratando-se da neurose, o que está em jogo é o recalcamento (Verdrängung), cujo retorno se constitui num sintoma; já, no caso do desmentido ou da recusa (Verleugnung), estratégia do sujeito da perversão, o retorno é o fetiche; e o mecanismo de defesa da psicose é a foraclusão (Verwerfung), tendo a alucinação como aquilo que retorna.

Quando se questiona o que mantém o sujeito estabilizado até a primeira crise, Soler (2007) apud Almeida (2017) destaca que, para Lacan (1956), a identificação 
imaginária do sujeito com o desejo da mãe seria o que daria esta manutenção, sendo quando ocorre a perda das identificações, a desestabilização de todo o aparelho psíquico ocorreria sendo o ponto no qual um psicótico desencadeia uma crise onde os delírios seriam tentativas de estabilização dadas a partir da criação de novas identificações (ALMEIDA, 2017).

\subsection{INTERVENÇÕES POSSÍVEIS NA PSICOSE}

Dentre as intervenções possíveis na psicose Monteiro e Queiroz (2006) destacam três formas sendo elas: o trabalho com o delírio, a via da trivialização e o trabalho com arte, todas criadas a partir das transferências múltiplas do contexto institucional.

Na psicose, conforme Almeida (2017), quando uma representação é abalada, uma dissolução imaginária acontece, as representações e identificações do sujeito psicótico são facilmente desconstruídas e, neste ponto, uma crise acontece, permanecendo até a elaboração de um delírio que dê a representação faltante ao indivíduo.

À vista disso, Monteiro e Queiroz (2006) destacam que no trabalho com o delírio, o analista deve buscar trabalhar não a desconstrução do delírio a todo custo pois, por ser um modo de expressão subjetiva ele deve ser considerado como uma via de entrada da Psicanálise para o mundo da psicose do sujeito e, a partir daí, destituí-lo da posição de objeto para o gozo do Outro e possibilitar o seu advento como sujeito (MONTEIRO; QUEIROZ, 2006).

Então, a partir da premissa de emancipação do sujeito da sua posição inicial de objeto de gozo do Outro, o psicanalista deverá trabalhar os delírios do paciente de tal forma que se crie uma metáfora delirante onde o significante e o significado se estabilizem criando um efeito de significação e, por consequência, estabilização da situação clínica do paciente (ALMEIDA, 2017; BARBIERE, 2000; MONTEIRO; QUEIROZ, 2006). 
Outra possibilidade a ser trabalhada no atendimento ao paciente psicótico nas Redes de Atenção Psicossocial é, conforme Monteiro e Queiroz (2006), a trivialização, que vai na contramão do delírio e é indicada quando este se torna ameaça para o paciente e para terceiros. Nesta perspectiva, o trabalho será focado em não valorizar o delírio do indivíduo focando em enfatizar outro aspecto que não a da fala do delirante, fazendo-o não permanecer no delírio minaz, buscando auxilia-lo a constituir novas formas subjetivas delirantes de se organizar que sejam menos nocivas ao indivíduo e a sociedade (MONTEIRO; QUEIROZ, 2006).

Por fim, o psicanalista tem a possibilidade de intervir através da arte produzida nas oficinas terapêuticas das instituições de saúde mental (MONTEIRO; QUEIROZ, 2016). Apesar de tal atividade não ser comumente ministrada por um psicólogo ou psicanalista, o especialista poderá trabalhar em conjunto com o profissional responsável que, normalmente é o terapeuta ocupacional, para tentar estabelecer uma articulação do trabalho produzido nas oficinas com a produção subjetiva do indivíduo (BARBIERE, 2000; MONTEIRO; QUEIROZ, 2016; SANTOS; OLIVEIRA, 2012).

Barbiere (2000), destaca a importância da arte visto que o objeto produzido de forma autêntica carrega uma marca singular de seu criador, sendo original e único, capaz de se tornar passivo de ser interpretado. A autora continua dizendo: "todo ato traz em si um dizer que demanda uma leitura. $O$ ato criativo, ao produzir um efeito de ser questionado, produz discurso, faz laço social" (BARBIERE, 2000, p. 2).

Desta forma, o ato de fazer arte é capaz de dar simbolização daquilo que o criador pretende dizer, fazendo com ele produza um discurso sobre si e possa dar significado a aquilo que the aparece sem representações (BARBIERE, 2000; MONTEIRO; QUEIROZ, 2016). Ao criar, o indivíduo poderá trabalhar e melhorar sua própria arte e as representações que ali estarão contidas (BARBIERE, 2000; MONTEIRO; QUEIROZ, 2016). 


\section{METODOLOGIA}

O presente trabalho consistiu em uma pesquisa bibliográfica onde a coleta de dados foi realizada exclusivamente através de materiais já elaborados sendo consultados diversos artigos científicos, livros, leis e portarias para então, analisar o conteúdo pertinente com a proposta de trabalho e condensá-los no presente estudo (GIL, 2002; SAMPIERE; COLLADO; LUCIO, 2010).

No que diz respeito às fontes consultadas, dentro dos periódicos, a predominâncias foi daqueles que se referiam a saúde mental e psicanálise e estavam em bases de dados relacionadas com o tema como o LILACS, havendo também outros mais generalistas. Já no que se refere aos livros pesquisados, foram utilizados aqueles que apresentavam estreita ligação com o tema tratado e os que referiam a metodologia de pesquisa cientifica.

Diante disso, para selecionar os textos técnicos pertinentes ao trabalho proposto, foram realizadas buscas em sites científicos sendo observados e utilizados os títulos e os resumos para a seleção ampla dos artigos que pudessem ter relação com a proposta do projeto. Para a realização da referida busca foram utilizadas diversas palavras-chave em conjunto e isoladamente, sendo que os principais termos utilizados foram psicanálise, psicótico, saúde mental e atenção psicossocial.

Por fim, foram selecionados textos preferencialmente nacionais, para melhor contextualização dos fatos que se queria averiguar e que estivessem entre os anos 1999 e 2020, dando maior preferência aos mais atuais, buscando um trabalho mais fidedigno com o cenário atual e seus nuances (GIL, 2002; SAMPIERE; COLLADO; LUCIO, 2010).

\section{CONCLUSÃO E CONSIDERAÇÕES FINAIS}

O presente artigo buscou trabalhar como se dá a inserção da Psicanálise no contexto das instituições de saúde mental e se dispôs a verificar a eficácia desta entrada para a elaboração do plano terapêutico e condução dos casos nestas organizações. 
Defronte do exposto, na preste pesquisa, é possível concluir que a inserção da Psicanálise no contexto institucional das entidades que fazem parte da Rede de Atenção Psicossocial (RAPS) poderá contribuir de forma impar para o avanço do processo de individualização dos trabalhos com os indivíduos psicóticos.

Por ser uma disciplina que busca a emancipação do sujeito e que pauta seus trabalhos em consonância ao que é trago pelo indivíduo criando, desta forma, um setting terapêutico individualizado para cada paciente acolhido, a Psicanálise poderá auxiliar na ampliação do olhar da equipe multiprofissional para o ser humano ali presente com suas potencialidades, dificuldades e saberes únicos sobre si e o mundo, auxiliando na condução do caso e na elaboração de um plano terapêutico único podendo pensar em características transdisciplinares e multidisciplinares de atendimento.

Além disto, o psicanalista quando inserido dentro deste contexto, poderá ajudar na resolução de conflitos internos à instituição que são inerentes às relações humanas e auxiliar a equipe a trabalhar com as divergências de olhares para com o paciente que são oriundas do campo pessoal e do trabalho multidisciplinar, visto que cada disciplina terá uma forma de enxergar a enfermidade do indivíduo. Portanto, a disciplina psicanalítica irá auxiliar no zelo para que tais questões e processos de ordem individual dos profissionais não interfiram nas ações realizadas pela equipe, prevenindo possíveis prejuízos na condução dos casos clínicos.

É percebido, frente a esta pesquisa, que a Psicanálise inserida no contexto das instituições de saúde mental é capaz de emergir sem se desviar de sua ética singular e abrirá um leque de possibilidades para atendimento dos indivíduos psicóticos. Sendo assim, o presente trabalho não esgotou (e nem pretendeu fazer isto) todos os cenários em que o advento dessa disciplina dentro das instituições da RAPS poderá dar seu apoio. A clínica psicanalítica por ser uma clínica feita para o paciente e por ele, faz com que toda a noção preconcebida pelo especialista seja colocada em segundo plano, tendo como concepção de que o indivíduo é mantenedor de sua experiência e a partir desta o especialista deverá elaborar um plano de trabalho, vindo ao encontro da premissa da extinção do saber centrado no especialista. 
Ademais, a Psicanálise possibilita o indivíduo psicótico emergir como sujeito, saindo da posição de gozo do Outro, passando a se elaborar a partir de uma nova concepção onde, por ser uma clínica feita diante do caso a caso, sua elaboração depende exclusivamente daquilo que o indivíduo apresenta como queixa, abrindo um leque de possibilidades para 0 analista trabalhar o que Ihe foi trago, cabendo a ele um certo felling para buscar a melhor forma para intervir e tratar a situação.

A função do especialista será a busca pela estabilização do indivíduo em um ponto que cause menos dano a ele, suas construções subjetivas e a sociedade. Destarte, o psicanalista deverá trabalhar auxiliando na elaboração de uma metáfora delirante que ocupe o lugar da metáfora anterior ao delírio que foi perdida, também podendo coadjuvar, na exploração, emersão e advento do sujeito a partir de outros vieses fora da clínica tradicional da Psicanálise. Deste jeito, dentro de algumas das instituições de saúde mental como o Centro de Atenção Psicossocial (CAPS), existe um leque enorme de possibilidades de trabalho do especialista a ser explorado, que o proporciona a ver e trabalhar com o indivíduo fora do setting do consultório e para além do discurso falado, como nas oficinas de arte, musicoterapia e assim por diante.

Portanto, o ambiente tido nas referências terapêuticas da RAPS, como nos Centro de Atenção Psicossocial (CAPS), oferecem ao analista uma oportunidade ímpar de observar o indivíduo e suas produções nas oficinas desta instituição, algo que na clínica tradicional é quase impossível, tanto pelo fato da pouca adesão do psicótico à clínica convencional quanto pelo tipo de espaço limitado que the é oferecido aberto tão somente, para produções oriundas da própria linguagem oral.

\section{IMPLICAÇÕES DA PESQUISA, SUGESTÕES PARA TRABALHOS FUTUROS}

Em face do exposto na presente pesquisa, identificou-se diversos benefícios da introdução de um psicanalista como parte dos profissionais que compõe a equipe de saúde mental para o atendimento de sujeitos psicóticos. Outrossim, outros benefícios foram observados para a equipe profissional e para a dinamização dos trabalhos de cunho terapêutico. 
Após finalizar este trabalho, várias dúvidas foram sanadas, entretanto diversas outras apareceram. Logo, este estudo possibilitou vislumbrar diversas contribuições da Psicanálise para a clínica de sujeitos psicóticos dentro das instituições da Rede de Atenção Psicossocial. Desse modo, espera-se que esta pesquisa se torne um meio contributivo para a avalição dos impactos da introdução de um especialista em Psicanálise dentro das equipes multiprofissionais de saúde mental.

Frente a isso, considerando as limitações da presente pesquisa bibliográfica, é sugerido estudos longitudinais que verifiquem a eficácia da entrada da Psicanálise nas oficinas de artes e musicoterapia onde, juntamente com o terapeuta ocupacional e outros profissionais, poderá auxiliar os pacientes psicóticos na elaboração subjetiva a partir de suas produções artísticas.

Por fim, é sugerido estudos que abarcam a possibilidade de verificação da eficácia do advento da disciplina psicanalítica dentro dos hospitais psiquiátricos para profissionais e pacientes, posto que existem poucas contribuições cientificas recentes acerca desta temática.

\section{REFERÊNCIAS}

ALBERTI, S. A política da psicanálise e a da saúde mental. Estudos e Pesquisas em

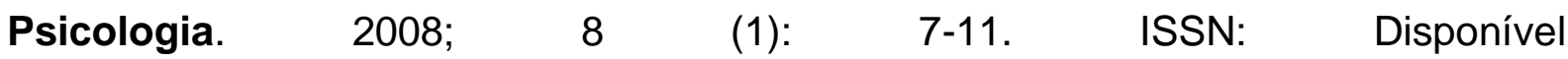
em: https://www.redalyc.org/articulo.oa?id=4518/451844616002. Acesso em 3 ago de 2020.

ALBERTI, S.; FULCO, A. P. L. Um estudo, uma denúncia e uma proposta: a psicanálise na interlocução com outros saberes em saúde mental, como avanço do conhecimento sobre o sofrimento psíquico. Revista Latinoamericana de Psicopatologia Fundamental, n.8, p.721-737, 2005.

ALMEIDA; R. M. G. de. As estabilizações na psicose: metáfora delirante e sinthoma. Revista Affectio Societatis, Colômbia, v. 14, n. 26, ISSN 0123-8884, jan-jun. 2017. Disponível em: 
<https://revistas.udea.edu.co/index.php/affectiosocietatis/article/view/325937> Acesso em 05 ago de 2020.

ARAGÃO E RAMIREZ, H. H. Sobre a metáfora paterna e a foraclusão do nome-dopai: uma introdução. Mental, Barbacena, v. 2, n. 3, p. 89-105, nov. 2004. Disponível em $<$ http://pepsic.bvsalud.org/scielo.php?script=sci_arttext\&pid=S1679$44272004000200008 \&$ Ing=pt\&nrm=iso> Acesso em 07 ago 2020.

BARBIERI, C. P. Psicanálise da criação: sublimação e repetição. Cogito, Salvador, v. 2, p. 21-28, $2000 . \quad$ Disponível em $<$ http://pepsic.bvsalud.org/scielo.php?script=sci_arttext\&pid=S151994792000000100003\&lng=pt\&nrm=iso>. acessos em 05 ago 2020.

BRAGA, M. L. S. As três categorias peircianas e os três registros lacanianos. Psicol. USP, São Paulo, v. 10, n. 2, p. 81-91, 1999.

BRASIL. Portaria no 3.088, de 23 de dezembro de 2011 (republicada 2013). Institui a Rede de Atenção Psicossocial para pessoas com sofrimento ou transtorno mental e com necessidades decorrentes do uso de crack, álcool e outras drogas, no âmbito do Sistema Único de Saúde (SUS). Diário Oficial [da] República Federativa do Brasil, 23 dez. 2011/2013.

COPPUS, A. N. S.; NETTO, M. V. R. F. A Inserção do Psicanalista em uma Unidade de Tratamento Intensivo. Psicol. cienc. prof., Brasília, v. 36, n. 1, p. 88100, mar. 2016.

FIGUEIREDO, A. C. A construção do caso clínico: uma contribuição da psicanálise à psicopatologia e à saúde mental. Rev. latinoam. psicopatol. fundam., São Paulo, v. 7, n. 1, p. 75-86, mar. 2004.

GIL, A. C. Como elaborar projetos de pesquisa. 4를 Ed. São Paulo: Atlas, 2002.

MARANHAO, Joyce Hilario; VIEIRA, Camilla Lopes Araújo. Reflexões sobre os conceitos de cidadania e sujeito em psicanálise na Atenção Psicossocial. Estud. 
pesqui. psicol., Rio de Janeiro, v. 19, n. 3, p. 753-771, set. 2019. Disponível em $<$ http://pepsic.bvsalud.org/scielo.php?script=sci_arttext\&pid=S1808$42812019000300012 \&$ Ing=pt\&nrm=iso $>$. acesso em 04 ago. 2020.

MONTEIRO, C. P.; QUEIROZ, E. F. de. A clínica psicanalítica das psicoses em instituições de saúde mental. Psicol. clin., Rio de Janeiro, v. 18, n. 1, p. 109-121, 2006.

NEVES, A. da S.; OMENA, N. A. de. A clínica de família no centro de atenção psicossocial III: psicose e configurações vinculares. Vínculo, São Paulo, v. 13, n. 1, p. 65-80, jun. 2016. Disponível em $<$ http://pepsic.bvsalud.org/scielo.php?script=sci_arttext\&pid=S1806$24902016000100007 \&$ Ing=pt\&nrm=iso>. acesso em 05 ago. 2020.

NOBREGA, M. do P. S. de S.; MANTOVANI, G. dos S.; DOMINGOS, A. M. Recursos, objetivos e diretrizes na estrutura de uma Rede de Atenção Psicossocial. Rev. Bras. Enferm. Brasília, v. 73, n. 1, e20170864, 2020.

PORGE, E. et al. (2015). Manifesto pela psicanálise. Rio de Janeiro: Civilização Brasileira.

SAMPIERI, R. H.; COLLADO, C. F.; LUCIO, M. P. B. (2010). Metodologia de Pesquisa. 5o Edição, Trad. Sob a direção de Daisy Vaz de Moraes. Porto Alegre, RS: Penso Editora.

SANTOS, T. C. dos; OLIVEIRA, F. L. G. de. Teoria e clínica psicanalítica da psicose em Freud e Lacan. Psicol. estud., Maringá, v. 17, n. 1, p. 73-82, Mar. 2012.

\section{APÊNDICE - REFERÊNCIAS DE NOTA DE RODAPÉ}

2. Para melhor compreensão da gênese e do mecanismo de funcionamento das psicoses a partir da ótica psicanalítica, recomenda-se a leitura do texto de Aragão e Ramirez (2004) na integra no website: 
http://pepsic.bvsalud.org/scielo.php?script=sci_arttext\&pid=S167944272004000200008 (acessado em 07 de agosto de 2020)

3. No conceito lacaniano o nome-do-pai é uma metáfora que diz respeito a um terceiro elemento que se apresenta entre a mãe e a criança, sendo este, o instaurador da lei no infante, demonstrando sua impossibilidade de completude e possibilitando a sua inscrição como sujeito de desejo (ARAGÃO E RAMIRES, 2004; BRAGA, 1999)

4. O Real é um dos três registros psíquicos e não deve ser confundido com a realidade na teoria psicanalítica, é aquele que está no lugar do irrepresentável, inatingível e da não-existência no discurso, aquele que não é alcançado pela linguagem e, por isto, ele não pode ser simbolizado, permanecendo impenetrável no sujeito (ARAGÃO E RAMIRES, 2004; BRAGA, 1999).

Enviado: Dezembro, 2020.

Aprovado: Dezembro, 2020. 